\title{
DETERMINANTS OF NEONATAL SEIZURE AMONG NEWBORNS ATTENDING A TERTIARY CARE HOSPITAL
}

\author{
Ara $\mathrm{R}^{1}, \mathrm{Uddin} \mathrm{MN}^{2}$
}

\begin{abstract}
Introduction: Neonatal seizure is an important cause of childhood mortality and morbidity. The prevalence of neonatal seizure is 2-3/1000 live births in term and 10-15/1000 preterm deliveries in our country. Proper neonatal care is crucial. Different study results representing the risk factors for neonatal seizure are directly and indirectly related.
\end{abstract}

Objectives: The study was carried out to determine the factors influencing neonatal seizure among the patients attending a tertiary care hospital.

Methods: A cross- sectional study was carried out to find out the factors of neonatal seizure where face to face interview was taken to 50 purposively selected respondents who were attending a tertiary care hospital during spring season. All the data were entered into a personal computer and thoroughly checked for any possible errors and then processed and analyzed by statistical Package for Social Science (SPSS) version 17 and MS office 2007.

Results: Among the total respondents mostly were of $<25$ years (Mean \pm Sd, $23.16 \pm 3.919$ ) of age. $36 \%$ had primary level education and $32 \%$ were illiterate. The mean monthly family income was 11392.0 \pm 11551.81 BDT. Respondents by pregnancy related complications were mostly of Pre-Eclamptic Toxemias (PET) in $22 \%$ cases and anaemia in $24 \%$ cases. Gestational age of the respondents was mainly $>37$ weeks. The study also reported that antenatal care by doctors was taken in $64 \%$ cases. Among the delivery related factors, most of the deliveries took place at home (64\%). Among the neonatal factors weight $<2 \mathrm{~kg}$ was found in $34 \%$ cases and $2.1-2.4 \mathrm{~kg}$ in $56 \%$ cases respectively.
Study also reported that the causes of seizures were Peri-natal Asphyxia (PNA) (12\%) and LBW $(11 \%)$. Respondents by onset of seizure were mostly within 24 hours (44\%), common types of seizure were subtle $(50 \%)$ and duration of seizures was found to be less than $5 \mathrm{~min}$ in (64\%) cases. The study also revealed the association between the causes and types of seizure; the result showed that $60 \%$ of subtle type of seizure was associated with Infant of Diabetic Mother (IDM) followed by focal type (40\%). PNA was associated with $58 \%$ of subtle type of seizure. Our result was found statistically insignificant $(p>0.05)$. Association of onset of seizure and birth weight of the neonates also revealed insignificant ( $p>0.05)$ result. This can be explained by small sample size and short duration of study. On the other hand other studies reported significant $(p<0.05)$ results as they had larger sample size and longer study period.

Conclusion: Maternal factors, neonatal factors and delivery related factors are related to neonatal seizure. Further studies involving larger sample size is recommended.

Key-words: Neonatal seizure, childhood mortality \& morbidity, perinatal asphyxia.

\section{Introduction}

The first month of life is one of the highest risk periods for neonatal seizures ${ }^{1,2}$. Seizure is the most common manifestation of neurological conditions in the neonate. The prevalence of seizure is $2-3 / 1000$ live births in term and 10-15/1000 in preterm deliveries. Neonatal seizure has been shown to be a major risk factor for in-patient deaths and subsequent neurological instability ${ }^{1,2}$.

1. Dr. Rowshan Ara, MBBS, MPH(MCH\&FP), MPhil(PSM), Asst Professor of Community Medicine, Dhaka Medical College, Dhaka; 2. Maj Gen Md Nasir Uddin, MBBS, MPH(HM), MPhil(PSM), Commandant, AFMC, Dhaka Cantt. 
A seizure is defined clinically as a paroxysmal alteration in neurological function i,e motor behavior and/or autonomic function ${ }^{2}$. Studies on neonatal seizures in developed nations have shown that most vital events are secondary to acute neurological insults such as hypoxic ischemic encephalopathy (HIE), stroke or infection ${ }^{1,3}$. Out of 125 neonatal encephalopathy cases, $28 \%$ were diagnosed as suffering from moderate or severe encephalopathy, whereas $36 \%$ had mild encephalopathy. Risk of neonatal encephalopathy increased with increasing or decreasing maternal age. There may be single seizures or multiple seizures. There were no differences in gender ${ }^{1}$.

The changing etiology profile of neonatal seizures over the years can be ascribed to advances in several areas. Among these are significant developments in obstetric and neonatal management that have changed the spectrum of insults to which the immature brain is exposed ${ }^{6,7}$. In addition, more accurate aetiologic diagnosis has been facilitated by advances in neuro-diagnostic technology, particularly in brain imaging ${ }^{1,8}$. Several studies have established the causes of neonatal seizures as well as the determinants of outcome among survivors, specifically at early onset of seizures ${ }^{9}$. Various global attempts were taken for reducing the mortalities associated with neonatal seizures, a common problem in neonatal practice. Most of the neonatal seizures are due to hypoxic-ischemic encephalopathy (HIE) secondary to perinatal asphyxia which is the commonest cause of seizure in neonates especially in developing countries and constitutes $50-60 \%$ of all seizures ${ }^{5}$. Majority of seizures start within $12 \mathrm{hrs}$, remaining have an onset within 24-48 hrs. Seizures followed by infection of secondary to intrauterine, metabolic causes may cause intracranial hemorrhage and developmental defect $^{2,3}$. Public health interventions aimed at ensuring safe deliveries, appropriate neonatal resuscitation and prevention of infections in the newborn period may help to reduce the high incidence. Prospective studies on long-term neurological and developmental outcome following neonatal seizures are needed ${ }^{12}$. Neonatal seizures continue to be a diagnostic and therapeutic challenge to the clinician.
Diagnostic and therapeutic interventions should thus be established promptly, for which proper classification and etiologic workup are pre-requisites ${ }^{9,10}$. Multiple determinants can co-exist in neonatal seizure and a comprehensive approach for the management of neonatal seizures is needed $^{2,5}$. The newborn care practice involving the diagnosis of neonatal seizure is based either on direct observation of the clinical and EEG event. Despite of increasingly sophisticated intensive care, clinical management of seizures remain challenged by difficult prognostic and therapeutic questions ${ }^{13}$. So, proper neonatal care is crucial. Different study results representing the risk factors for neonatal seizures have been directly and indirectly related. The gaps identified within the first week of life is very important for immature brain ${ }^{14,15}$. Home delivery without any antenatal care and maternal complications leading to neonatal death were some identifiable factors in this study. Therefore this study sought to identify some risk factors of neonatal seizure in our perspective. This may help stakeholders in policy development towards achieving Millennium Development Goals (MDG) ${ }^{16,17}$.

\section{Materials and Methods}

The study was a descriptive cross-sectional type and was conducted in the neonatal ward of Dhaka Medical College Hospital, Dhaka. Study period and duration was four months; from December 2013 to March 2014. All the neonates aged within 28 days with the mothers were admitted in neonatal ward with or without seizures. Sample size was 50 for one year study. The neonate patients attending the hospital for seizure within the study period were included as study population. Purposive sample technique was adopted for collection of data from the study population. In the study, data collection tools were pretested by semi-structured questionnaires, check-list and examination instruments were torch light, weighing scale and stethoscope. Data was collected by face to face interview with mother /care giver and physical examination. Subjects were taken from the neonatal ward of Paediatric Department of Dhaka Medical College Hospital according to the selection criteria. Detailed history was taken by face to face interview and thorough physical examination was performed for all cases. 
All the data were entered into a personal computer and thoroughly checked for any possible errors and then processed and analyzed by statistical Package for Social Science (SPSS) version 17 and MS office 2007.

\section{Results}

Table-I shows that majority of the $(76.0 \%, \mathrm{n}=38)$ respondents belonged to $<25$ years age group followed by $16 \%,(n=8)$ and $8 \%(n=4)$ of $25-29$ years $\& \geq 30$ years and mean age was $23.16+3.919$ years.

Table-I: Distribution of the mother's status by age $(n=50)$.

\begin{tabular}{|l|c|c|}
\hline Age of the mother & Frequency & Percentage \\
\hline$<25$ years & 38 & $76.0 \%$ \\
\hline $25-29$ years & 8 & $16.0 \%$ \\
\hline$\geq 30$ years & 4 & $8.0 \%$ \\
\hline Total & $\mathbf{5 0}$ & $\mathbf{1 0 0}$ \\
\hline
\end{tabular}

Table-II shows the educational level of the respondents; majority of the respondents $(36 \%$, $\mathrm{n}=18$ ) got primary level education followed by no education (32\%, $n=16)$. On the other hand $14 \%$ $(n=7)$ had SSC, 12\% $(n=6)$ had HSC and 6\% (03) had degree and above level of education respectively.

Table-II: Distribution of the mother's status by education $(n=50)$.

\begin{tabular}{|l|c|c|}
\hline Education & Frequency $\mathbf{( n )}$ & Percentage \\
\hline Illiterate & 16 & 32.0 \\
\hline Primary & 18 & 36.0 \\
\hline SSC & 7 & 14.0 \\
\hline HSC & 6 & 12.0 \\
\hline Degree/above & 3 & 6.0 \\
\hline Total & $\mathbf{5 0}$ & $\mathbf{1 0 0 . 0}$ \\
\hline
\end{tabular}

Fig-1: Distribution of respondents by monthly family income ( $n-50)$.

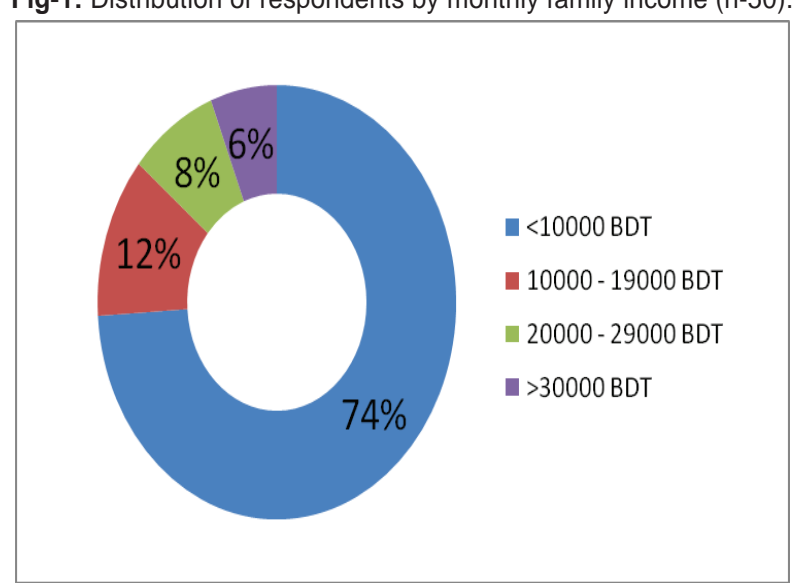

Figure- 1 shows the distribution of all respondents by their monthly income; $74.0 \%$ had monthly income of $<10000$ Taka, $12 \%$ had Taka-10000 to 19000 , $8 \%$ of them had income of Taka-20000 to 29000 and $6 \%$ of $>30000$ Taka BDT respectively.

Fig-2: Distribution of respondents by various types of neonatal seizures $(n-50)$.

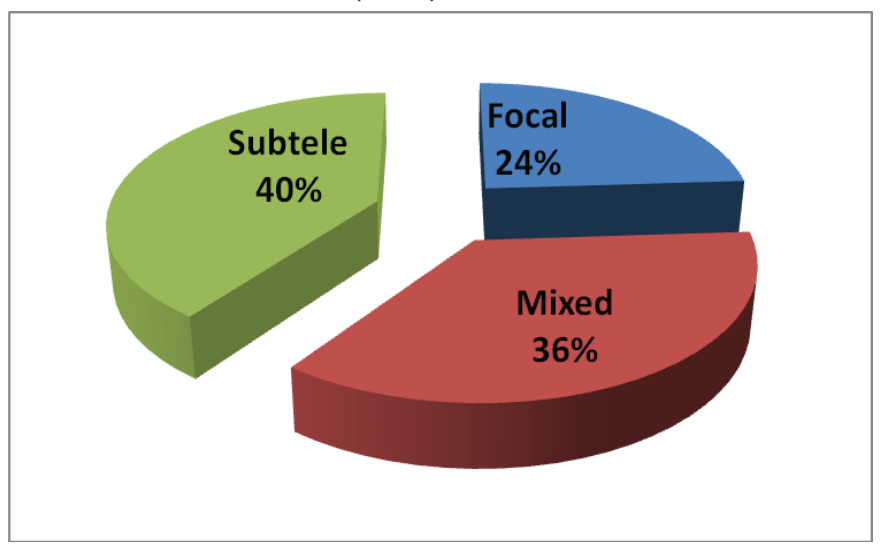

Figure-2 shows that subtle type was noticed in twenty $(40 \%, n=20)$ cases, focal type in twelve $(24 \%, n=12)$ and mixed subtle and focal were found in eighteen $(36 \%, n=18)$ cases. Generalized tonic-clonic and myoclonic types were not found but blinking of eye, eye deviation, cyclical movement of limbs were considered as manifestation of subtle seizure activity.

Fig-3: Distribution of respondents by age of onset of neonatal seizures $(n=50)$.

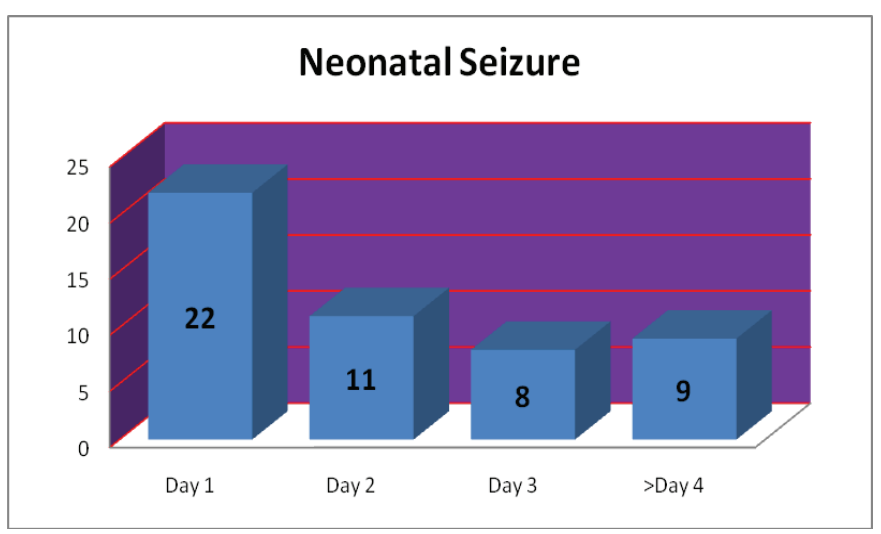

Figure-3 shows majority of seizures occured in day one or within 24 hours $(46 \% \mathrm{n}=22)$ followed by day 2 or 48 hours $(22 \%, n=11)$, day $3(18 \%, n=8)$ and lastly day $4(14 \%, n=9)$ respectively. 
Fig-4: Distribution of the respondents by pregnancy related complications $(n-50)$.

\section{Pregnancy Related Complications}

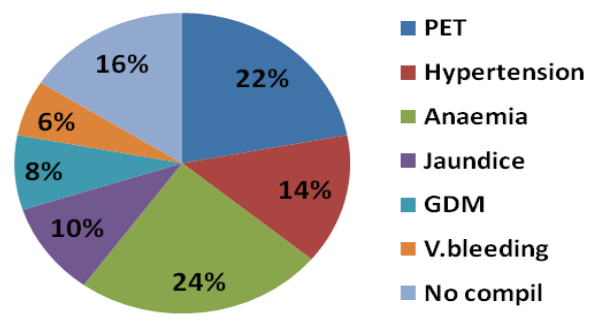

Figure-4 shows maternal complications during pregnancy as PET (pre-eclamptic toxaemia (22\%, $n=11)$, hypertension ( $14 \%, n=7)$, anaemia in pregnancy (24\%, n=12), GDM (Gestational Diabetes mellitus) $(10 \%, n=5)$, jaundice $(8 \%, n=4)$, vaginal bleeding in pregnancy $(6 \%, n=3)$ and normal or no complication was found in $16 \%$ cases $(n=8)$ respectively.

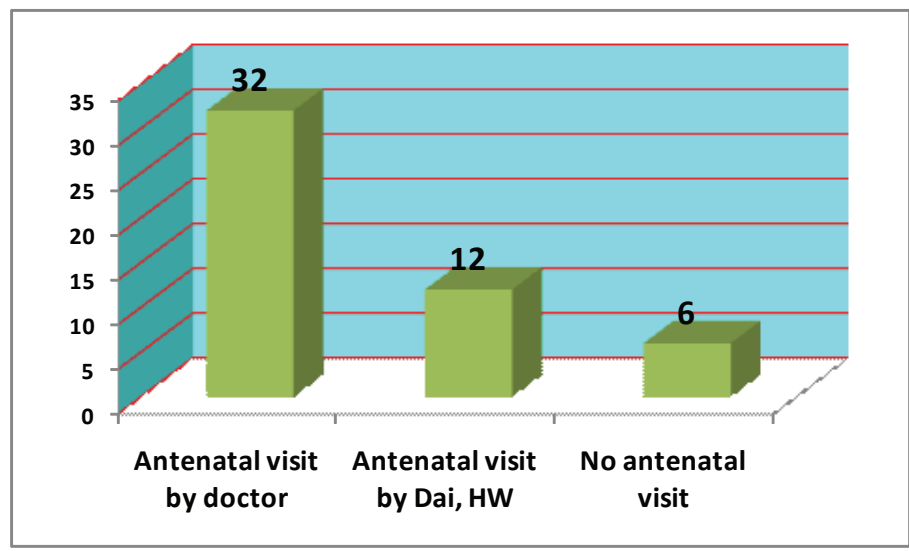

Figure- 5 shows antenatal visit of the respondents; majority $(64 \%, n=32)$ went for antenatal visit to qualified doctors where as $24 \% \quad(n=12)$ visited to unqualified health workers (Dai,FHV) and 12\% ( $n=6)$ had no antenatal visit.

Fig-6: Distribution of respondents by gestational age (n-50).

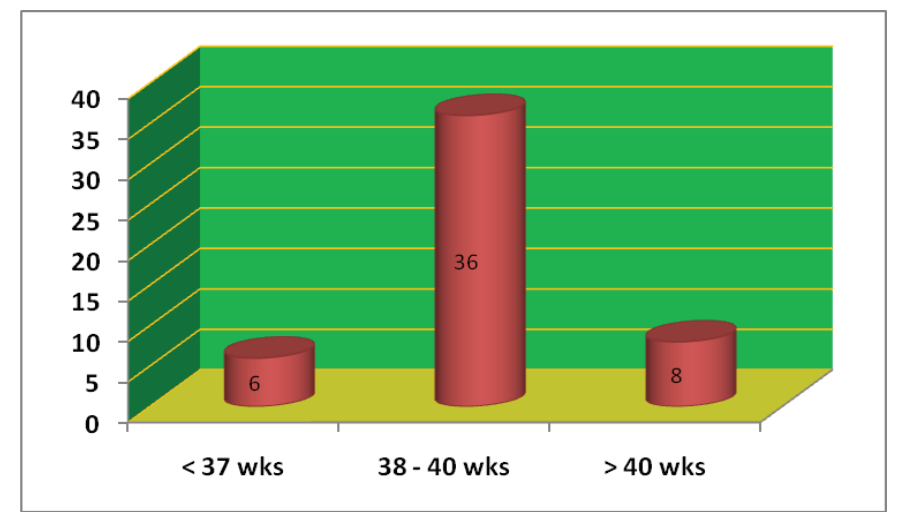

Figure- 6 shows the gestational age of respondents as $\leq 37$ weeks $(12 \%, n=6), \quad 38-40$ weeks $(72 \%, \mathrm{n}=36)$ and $>40$ weeks $(8 \%, \mathrm{n}=16)$ respectively.

Table-III Shows place of delivery as home delivery $(64 \%, n=32)$, tertiary care hospital delivery $(20 \%, n=10)$ and delivery in clinic $(16 \%, n=8)$ respectively. Mode of delivery was vaginal (normal) in $58 \%(n=29)$ cases and by LUCS in $42 \%(n=21)$ cases.

Table-III: Distribution of respondents by mode and place of delivery ( $n-50)$.

\begin{tabular}{|l|l|c|c|c|}
\hline \multicolumn{2}{|c|}{ Delivery } & Frequency & Percent (\%) & Total \\
\hline \multirow{2}{*}{$\begin{array}{l}\text { Place of } \\
\text { delivery }\end{array}$} & Home & 32 & 64.0 & \multirow{1}{*}{100.0} \\
\cline { 2 - 4 } & Hospital & 10 & 20.0 & \\
\cline { 2 - 4 } & Clinic & 8 & 16.0 & \\
\hline \multirow{2}{*}{$\begin{array}{c}\text { Mode of } \\
\text { delivery }\end{array}$} & $\begin{array}{l}\text { Vaginal } \\
\text { (Normal) }\end{array}$ & 29 & 58.0 & \multirow{2}{*}{100.0} \\
\cline { 2 - 4 } & LUCS & 21 & 42.0 & \\
\hline
\end{tabular}

Fig-7: Distribution of neonates by sex $(n-50)$.

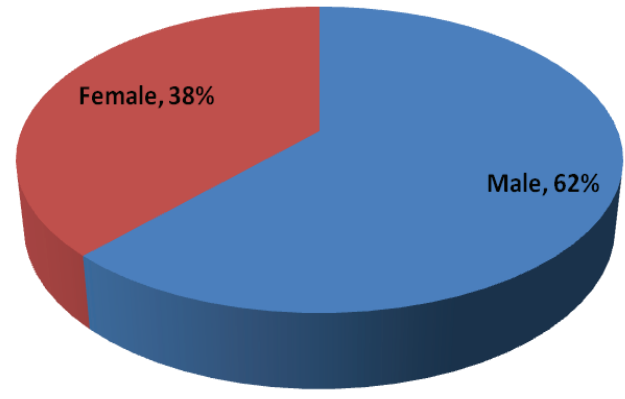

Figure-7, Pie diagram shows that the studied neonates were $62 \%(n=31)$ male and $38 \%(n=31)$ were female.

Fig-8: Weight distribution of the studied neonates ( $n-50)$.

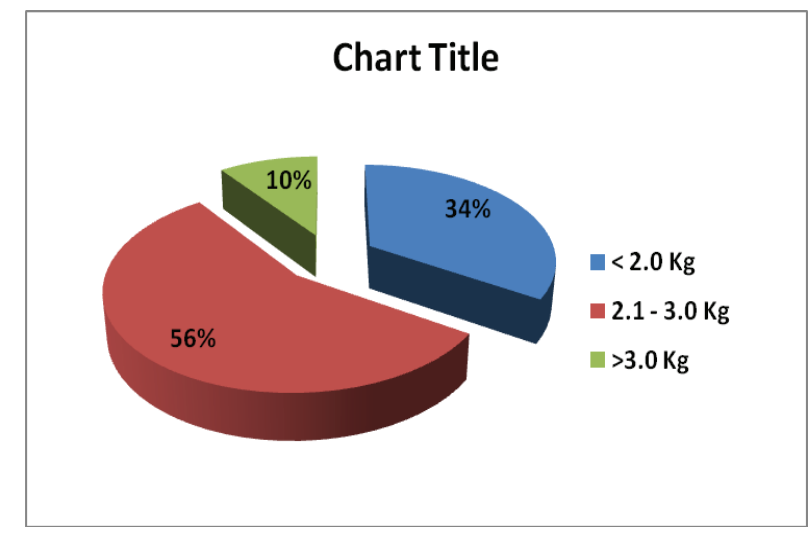


Figure-8 shows weight of the studied neonates were $2.1-3 \mathrm{~kg}(56 \%, \mathrm{n}=28), \leq 2 \mathrm{~kg}(34 \%, \mathrm{n}=17)$ and lastly $>3 \mathrm{~kg}$ was $(10 \%, \mathrm{n}=5)$ respectively.

Fig-9: Distribution of causes of neonatal seizures $(n=50)$.

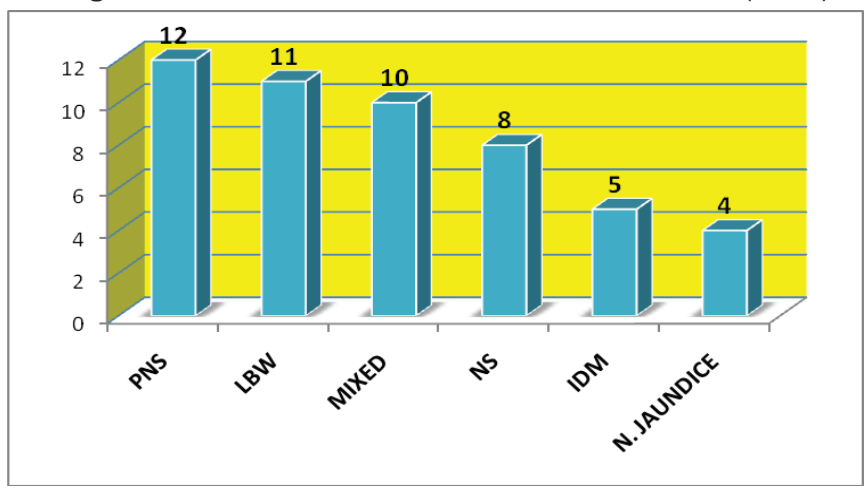

Figure-9, Bar diagram shows the causes of seizures in studied cases. Majority were PNS (Perinatal Asphyxia) $(24 \%, n=12)$ and low birth weight $(22 \%$, $n=11)$ followed by mixed $(20 \%, n-10)$, neonatal sepsis $(16 \%, n=8)$, IDM (Infant of diabetic mother) $(10 \%, n=5)$ and lastly neonatal jaundice $(8 \%, n=4)$ respectively.

Table-IV shows duration of seizures. Thirty two (64\%, n=32) babies had convulsion of less than 5 minute duration followed by eighteen $(36 \%, n=18)$ of more than 5 minutes.

Table-IV: Duration of neonatal seizure ( $n-50)$.

\begin{tabular}{|l|c|c|}
\hline Duration (min) & Frequency & percentage \\
\hline$<5$ & 32 & $64 \%$ \\
\hline $5-30$ & 18 & $36 \%$ \\
\hline
\end{tabular}

Table- $V$ shows the distribution of gestational age of the respondents and neonatal seizures. The result found that $57 \%$ of neonates who were less than 37 weeks i, e preterm developed seizure in 1day (within 24 hours). On the other hand $27 \%$ developed seizure after 48 hours or second day onwards.

Table-V: Distribution of respondents by gestational age \& neonatal seizure.

\begin{tabular}{|l|c|c|c|c|c|}
\hline \multirow{2}{*}{ Gestational Age } & \multicolumn{4}{|c|}{ Seizure } & \multirow{2}{*}{ Total } \\
\cline { 2 - 5 } & Day 1 & Day 2 & Day 3 & $>$ Day 4 & \\
\hline$<37$ weeks & $8(57.1 \%)$ & $1(7.1 \%)$ & $3(21.4 \%)$ & $2(14.3 \%)$ & $14(100.0 \%)$ \\
\hline$>37$ weeks & $14(38.9 \%)$ & $10(27.8 \%)$ & $5(13.9 \%)$ & $7(19.4 \%)$ & $36(00.0 \%)$ \\
\hline Total & $22(44.0 \%)$ & $11(22.0 \%)$ & $8(16.0 \%)$ & $9(18.0 \%)$ & $50(100.0 \%)$ \\
\hline
\end{tabular}

Table-VI shows the distribution of causes and type of seizure, the results found that majority of subtle type of seizure were common in PNA, IDM, NS and neonatal jaundice whereas focal type of seizure was commonly associated with LBW (45\%) and IDM (40\%).

Table-VI: Distribution of respondents by causes \& type of seizure $(n=50)$.

\begin{tabular}{|l|c|c|c|c|}
\hline \multirow{2}{*}{ Causes } & \multicolumn{3}{|c|}{ Type of seizure } & \multirow{2}{*}{ Total } \\
\cline { 2 - 4 } & Subtle & Focal & Mixed & \\
\hline Perinatal Asphyxia & $7(58.3 \%)$ & $4(33.3 \%)$ & $1(8.3 \%)$ & $12(100.0 \%)$ \\
\hline low birth weight & $2(18.2 \%)$ & $5(45.5 \%)$ & $4(36.4 \%)$ & $11(100.0 \%)$ \\
\hline Mixed & $7(70.0 \%)$ & $1(10.0 \%)$ & $2(20.0 \%)$ & $10(100.0 \%)$ \\
\hline Neonatal sepsis & $4(50.0 \%)$ & $2(25.0 \%)$ & $2(25.0 \%)$ & $8(100.0 \%)$ \\
\hline Infant of diabetic mother & $3(60.0 \%)$ & $2(40.0 \%)$ & $0(.0 \%)$ & $5(100.0 \%)$ \\
\hline Neonatal Jaudice & $2(50.0 \%)$ & $1(25.0 \%)$ & $1(25.0 \%)$ & $4(100.0 \%)$ \\
\hline Total & $25(50.0 \%)$ & $15(30.0 \%)$ & $10(20.0 \%)$ & $50(100.0 \%)$ \\
\hline
\end{tabular}

\section{Discussion}

This cross-sectional type of descriptive study was carried out to determine the factors influencing neonatal seizure among the patients attending a tertiary care hospital. The significance lies in the magnitude of associated morbidities and mortalities. The developing brain has an increased susceptibility to seizure activity because of its immaturity. Therefore neonatal seizure may adversely affect brain function and may cause more damage among neonates than older children ${ }^{1,2}$. In socio-demographic factors-majority of the respondents age were less than 25 years; teenage pregnancy as well as elderly prime have some impact on neonatal seizure specially in developing countries ${ }^{1,2}$. Similar finding was reported in India and $\mathrm{Nepal}^{3,4}$ By education of the respondents, about more than fifty percent completed their primary education where as only $10 \%-15 \%$ completed their secondary and higher secondary education. Maternal education has direct relation with neonatal seizures ${ }^{6,7}$.

In present study, majority of the respondents monthly family income was less than 10,000 BDT and more than $10 \%$ respondents family income was average. As sample size was very small, so no significant association exists between monthly family income and prevalence of neonatal seizure. But other study findings had some relation with socio-demographic factors and neonatal seizures ${ }^{9,10}$. In this study respondent by sex distribution showed that more than half were male and one fourth were female. In our study male sex preponderance was found which was consistent with other studies. Sanjeev et al and Udani so reported similar results ${ }^{11,20,21}$. 
In Indian subcontinent, it is often seen that male babies are usually cared better by their parents and are brought to the hospital with even minor complaints but female babies are usually neglected and are managed at home even if they are very sick $^{15,16,18}$. Regarding weight distribution of the respondents in this study, more than $50 \%$ were within $2.1-3 \mathrm{~kg}$ group and $34 \%$ were of less than 2 $\mathrm{kg}$ which was also described as low birth weight (LBW). Literature review reported the LBW had some relation with neonatal seizures ${ }^{17,23}$.

In this study representing the causes of neonatal seizures, perinatal asphyxia was found to be the major cause leading to hypoxic ischemic encephalopathy which was the most dominant factor towards neonatal seizures followed by low birth weight (LBW) and early onset neonatal sepsis (EONS) respectively. Our findings are in consistence with other study results ${ }^{23,24}$. Regarding the gestational age, less than 37 weeks or preterm contributed for neonatal seizures. Our clinical findings were also comparable with other studies ${ }^{17,26}$. Majority of the respondents received antenatal care and the deliveries were conducted by qualified doctors. On the other hand, nearly $25 \%$ had no antenatal visit and delivery was conducted by dai / health workers at home. Home delivery with prolonged labour has direct relation with neonatal seizure. Some of the studies in developing countries has similar findings ${ }^{10,16,18}$. Rehena Majeed et al in her study showed ante-natal care was received by only $12 \%$ of study population. Mode of delivery in the respondents was mostly normal vaginal and LUCS was done in $42 \%$ cases. These findings are similar with other studies ${ }^{29}$. Complications among the respondents found were mainly PET and anaemia which remained as significant risk factors followed by hypertension and subsequently gestational diabetes, vaginal bleeding and jaundice. All these factors contributed to neonatal seizure. These findings are consistent with other study reports ${ }^{6,26}$. Gestational age of less than 37 wks which was considered as preterm also had significant contribution to neonatal seizure, these findings are also relevant with other study results ${ }^{22,24}$. In the present study, it is seen that early onset of seizure was within 24 hours i.e. in the first day of life, this was most probably due to perinatal asphyxia and seizures also occured in day 3 to 4 respectively. This observation was similar with other studies. After 4th day, seizure was due to septicemia which was one of the important contributing risk factors for seizure ${ }^{30,31}$. The high incidence of early onset of seizures in our and other studies can be explained by the fact that birth asphyxia was the most dominant factor contributing towards neonatal seizure. In our study, types of seizures were described clinically ${ }^{26}$; predominant type was subtle $(50 \%)$ followed by focal $(30 \%)$ and mixed type (20\%) whereas a study by Taksande AM et al reported that generalized, tonic, clonic myoclonic were the main types found in their study. Duration of seizure was less than 5 second in $64 \%$ cases whereas more than 5 seconds in $26 \%$ cases which was also comparable with other studies ${ }^{17,18}$.

Regarding association between causes of seizure and types of seizure, the study result found that subtle type of seizure was associated with IDM followed by focal type, PNA was also associated with subtle type of seizure. On the other hand, in other respondents seizure was associated with mixed cases and also with LBW and neonatal sepsis. Our study results were found to be statistically insignificant as because sample size was very small and it was also the limitation of the study. Whereas in other large sample size studies associated seizure with PNA and LBW was statistically significant $(p<0.05)^{6,19,25}$.

Regarding association of onset of seizure with birth weight of the neonates; the study group of less than $2 \mathrm{~kg}$ weight termed as LBW and more than $3 \mathrm{~kg}$ wiight (IDM cases) also developed seizure within 24 hours of birth. The results were statistically insignificant $(p<0.05)$; this can be explained by the small sample size .On the other hand, other study findings showed statistically significant association between birth weight and onset of seizure ${ }^{26,27}$. Our study also represented that there was association between delivery place and complications during pregnancy; in home delivery complication occured in $87 \%$ cases whereas in facility delivery places complications were present only in $16 \%$ cases. There was no statistically significant result in our study as our sample size was small and study period was limited but other large scale similar studies reported significant association $(p<0.05)^{28,32}$. The study shows that maternal factors, neonatal factors and some delivery related factors are directly and indirectly contributing for neonatal seizures. 


\section{Conclusion}

From the study it is revealed that most of the seizures occured within 24 hours of birth and common types of seizures are of subtle type followed by focal and mixed. The neonatal factors were prenatal asphyxia followed by low birth weight and neonatal sepsis, prolonged neonatal jaundice and infant of diabetic mother. Maternal factors were PET, hypertension, anaemia; improper gestational age followed by Gestational Diabetes Mellitus (GDM) which were important contributing factors for neonatal seizure. Deliveres conducted at home and lack of antenatal care were also seen to be important contribuing factors for neonatal seizures. Identifying the risk factors as sought in this study may play a crucial role in policy development for better management of these patients of neonatal seizure.

\section{References}

1. Michael M, Mathenge A, Samson G, Neema M, Evasius B, Charles RJC, Newton, James B. Neonatal seizures in a rural Kenyan District Hospital aetiology BMC Medicine 2010; 8: 16-20.

2. Rahaman MM, Narayan CS, Mannan A. Neonatal seizure: An update Bangladesh Journal of Child Health $2008 ; 32: 21-8$.

3. Digra SK, Gupta A. Prevalence of Seizures in Hospitalized Neonates. JK Science 2007; 9: 27-9.

4. Vento $M$, Vries IS, Alberola A, Blennow M, Steggerda S, Greisen G, Boronat N. Approach to seizures in the neonatal period: A European perspective. Acta Paediatr 2010;1.

5. Futrakul S, Praisuwanna P, Thaitumyanon P. Risk factors for hypoxic-ischemic encephalopathy in asphyxiated newborn infants. J Med Assoc Thai. $2006 \mathrm{Mar} ; 89(3): 32$.

6. Rennie JM, Boylan GB. Neonatal seizures and their treatment. Curr Opin Neurol 2003; 16:177-81.

7. Udani V. Long-term prognosis of Neonatal seizures where are we?. Neu;rology 2007;.69 :1816-22.

8. Ogunlesi T, Adekanmbi F, Fetuga B, Ogunfowora $\mathrm{O}$, Ogundeyi M. Risk factors for mortality in neonatal seizure in a Nigerian newborn unit.SA Journal of child Health. July 2007; 1: 64-7.
9. Tekgul K, Gauvreau K, Soul J, Murphy L, Robertson R, Stewart $\mathrm{J}$ et all. The current etiologic profile and neurodevelopment outcome of seizures in term newborn infants. American Academy of Paediatrics 2006 :117: 1270-4.

10. Shetty SS, Harrison LH, Haijeh RA, Taylor T, Mirza SA, Sehmidt AB et all. Determining risk factors for candidemia among new born infants from population-based surveillance: Baltimore, Maryland, 1998-2000.Pediatr Infect Dis J. 2005; 601-4.

11. Lanska MJ, Lanska DJ, Baumann RJ, Kryscio RJ. A population-based study of neonatal seizures in Fayette County, Kentucky. Neurology. 1995 Apr;45(4):724-32.

12. Saliba RM , Annegers FJ, Waller DK, Tyson JE, Eli M. Mizrahi EM.Risk Factors for Neonatal Seizures: A Population-based Study, Harris County, Texas, 1992-1994. Am. J. Epidemiol. (2001) 154 (1): 14-20.

13. Gebremarian A, Gutema $Y$, Leuel A, Fekadu H. Early-onset neonatal seizures: types, risk factors and short-term outcome. Ann Trop Paediatr 2006; 26:127-31.

14. Arpino C, Domizio S, Carrieri MP, Carrier MP, Brescianin DS, Sabatino MG et all. Prenatal perinatal determinants of neonatal seizures occurring in the first week of life. J Child Neurol 2001 ;16 (9):651-6.

15. Faye S, Silverstein MD .Do seizures contribute to neonatal hypoxic-ischemic brain injury? J Pediatr $2009 ;$ 155:305-6.

16. Save the Children. State of the world's mothers 2006: Saving the lives of mothers and newborns. Washington \{internet.2006 |cited] 2011 Aug 10.Avilable from www.who.int/pmnch/media/publication/aonend.pdf.

17. Lype M, Prasad M, Nair PM, Geetha S, Kailas L. The newborn with seizures- a follow-up study. Indian Pediatr. 2008 Sep;45(9):749-52.

18. Tekgul H, Gauvreau K, Soul J, Murphy L, Robertson $\mathrm{R}$, Stewart $\mathrm{J}$ et all. The current etiologic profile and neurodevelopmental outcome of seizures in term newborn infants.2006 Apr;117(4):1270-80. 
19. Pisani F, Sisti L, Seri S. A scoring system for early prognostic assessment after neonatal seizures. Pediatrics. 2009; 124(4): 580-7.

20. Rennie JM, Boylan GB. Neonatal seizures and their treatment. Curr Opin Neurol 2003; 16:177-81.

21. Holmes GL, Khazipov R, Ben-Ari Y. New concepts in neonatal seizures. Neuro Report 2002; 13-8.

22. Mizrahi EM. Neonatal seizures. In: Swaiman FK, Ashwal S, Ferriero MD, editors. Pediatric Neurology: Principles \& practice. Philadelphia: Mosby, Elsevier 2006: 257-78.

23. Volpe JJ. Neonatal seizures. In: Neurology of the newborn. 4th ed. Philadalphia: WB Saunders 1999; 15-35. 21. Faye S, Silverstein MD.Do seizures contribute to neonatal hypoxic-ischemic brain injury? J Pediatr 2009 ; 155:305-6.

24. Save the Children. State of the world's mothers 2006: Saving the lives of mothers and newborns. Washington \{internet.2006 |cited] 2011 Aug 10.Avilable from www.who.int/pmnch/media/publication/aonend.pdf.

25. Pisani F, Sisti L, Seri S. A scoring system for early prognostic assessment after neonatal seizures. Pediatrics. 2009; 124(4): 580-7.
26. Holmes GL, Khazipov R, Ben-Ari Y. New concepts in neonatal seizures. Neuro Report 2002; 13-8.

27. Mizrahi EM. Neonatal seizures. In: Swaiman FK, Ashwal S, Ferriero MD, editors. Pediatric Neurology: Principles \& practice. Philadelphia: Mosby, Elsevier 2006: 257-78.

28. Volpe JJ. Neonatal seizures. In: Neurology of the newborn. 4th ed. Philadalphia: WB Saunders 1999; 15-35.

29. Uria-Avellanal C, Marlow N, Rennie JM. Outcome following neonatal seizures.Semin Fetal Neonatal Med. 2013 Feb 25.

30. Sadeghian A, Damghanian M, Shanriian M. Neonatal seizures in a rural Iranian district hospital: etiologies, incidence and predicting factors.. Acta Med Iran 2012 I 50(11); 760-4.

31. Yildiz EP, Tati B, Ekici B, Erasign E, Aydinli N, Caliskan M. Evaluation of atiologic and prognostic factors in neonatal convulsions.Pediatr Neurol; 2012l 47(3):186-92.

32. Gabriel MR, David, Sharon PRN, David L, Streiner. Long -term prognosis in children with neonatal seizures A population based study. Neurology 2007; 69: 1816-22. 